\title{
Resistance to extinction of the CER as a function of shock-reinforcement training schedules ${ }^{1}$
}

\author{
CYNTHIA SCHEUER, Florida Atlantic \\ University, Boca Raton, Fla. 33432
}

Resistance to extinction of the CER in rats was determined at five shock-reinforcement values $(100,66,26$, 20 , and 13\%). The percentage of times the US followed the CS during conditioning was approached gradually, starting at $100 \%$, with subsequent reductions to a final schedule that differed for each of the partial groups. The data revealed an inverse-PRE, with greatest resistance to extinction of suppression at $100 \%$ shock-reinforcement. An interpretation, relating differences in shock density to the maintenance of generalized suppression, was suggested.

The present research was concerned with a parametric investigation of the effects of partial shock-reinforcement schedules on resistance to extinction of conditioned suppression (CER). Much of the partial-reinforcement literature suggests that the PRE in classical-conditioning experiments often takes on the form of an inverted-U (Lewis, 1960). Resistance to extinction is usually greatest at $50 \%-75 \%$, and drops off markedly at schedules above and below these values. Inadequate conditioning at the low percentages generally produces relatively poor asymptotic acquisition performance in some partially reinforced Ss (Grant \& Schipper, 1952). Consequently, these groups tend to extinguish relatively rapidly. To insure comparable asymptotic suppression levels in the present study, all Ss were initially trained on a $100 \%$ shock-reinforcement schedule. This percentage was gradually reduced to a final schedule that differed for each of the partial groups. With such a shaping procedure, a decline in resistance to extinction due to insufficient conditioning at the low percentages should be eliminated.

\section{SUBJECTS}

Twenty-five male albino rats of the Sprague-Dawley/Holtzman strain served as experimental Ss. The animals were 100-120 days of age at the start of preliminary barpress training. One animal died during the course of the experiment, and another was discarded for a failure to condition, leaving a total of $23 \mathrm{Ss}$ from which data were ottained.

\section{APPARATUS}

The apparatus consisted of two sound-attenuated operant-conditioning test chambers for rats (LVE 1316c). Each chamber was equipped with an LVE rat lever that required an operating forced equal to $14 \mathrm{~g}$. The reinforcement mechanisms, liquid dippers, supplied $.05 \mathrm{cc}$ of water to the animal at each presentation. Shock was supplied by two LVE shock generators and auxiliary scanners. These sources provided $.2 \mathrm{sec}$ scrambled shock to S's feet by electrifying grids that ran the length of the test-box floor. Shock intensity was calibrated across the grids with an ac Weston milliammeter in series with a $100 \mathrm{~K}$ ohm resistor. Dial settings on each source were adjusted to deliver $.5 \mathrm{~mA}$ shock to the animal. A repetitive clicking noise $(4 \mathrm{~Hz}$, approximately $80 \mathrm{~dB}$ ) served as the CS. A constant masking noise was provided in the room in which the experimental chambers were located. This noise was produced by a Grason-Stadler 901 white-noise generator.

Daily measures of suppression were obtained for each $\mathbf{S}$ during the extinction series by means of a Presin multiple-channel printout counter. All other events were automatically programmed and recorded by means of relay switching and timing circuits located in an adjoining room.

\section{PROCEDURE}

Phase 1. Establishment of the Baseline

Schedule of Positive Reinforcement

Following 1 week of adaptation to a 23-h water-deprivation cycle, all Ss were trained to barpress for water on CRF and then assigned at random to one of the two test chambers. Thus, 12 Ss were tested in one chamber, and 11 were tested in the other. Each $S$ was tested in 90-min daily sessions 7 days per week. At the end of each session, $S$ was permitted free access to water for $15 \mathrm{~min}$ in individual watering boxes and then returned to its home cage. Food, consisting of Purina Lab Chow pellets, was continuously available except during the 90-min test session.

Following initial conditioning of the lever-press response, the reinforcement requirement was gradually raised from CRF until response rates stabilized on a VI 3-min water-reinforcement schedule.

Phase 2. Training of the Conditioned Emotional Response (CER)

When stable rates were obtained on the VI 3 contingency, each $S$ was given 15 daily presentations of a 25 -sec clicking noise (CS). These CS presentations were randomly spaced over the 90 -min test session, and were superimposed upon and presented independently of the baseline schedule of positive reinforcement. Simultaneously with CS offset, an unavoidable electric shock was presented. During this phase of
CER acquisition, every CS terminated with shock.

Suppression of lever pressing was calculated by a "suppression ratio," B/A + B (Annau \& Kamin, 1961), where B represents the number of responses emitted during CS periods, and $A$ represents the number of responses emitted during the $25 \mathrm{sec}$ just prior to CS onset. Thus, a ratio of .00 indicates an absence of responding during CS periods, and .50 indicates no effect of the CS.

Prior to introducing partial shock-reinforcement, each $\mathrm{S}$ was required to demonstrate a mean daily suppression ratio of .10 or less for three consecutive test sessions following a minimum of 3 days at $100 \%$ shock-reinforcement. Only after this behavioral criterion was met was the percentage of CS-US pairings reduced.

Phase 3. Partial Reinforcement of the CER

When all Ss had achieved criterion-suppression measures at $100 \%$ daily CS-US pairings, four of the five groups were subjected to a gradual reduction in percentage of CS-US pairings, while the fifth group was maintained at $100 \%$. Although the number of daily $\mathrm{CS}$ presentations remained as in Phase 2, the percentage of times the CS terminated with shock was varied. CS-shock pairings were gradually reduced until criterion-suppression levels were obtained at $66 \%, 26 \%, 20 \%$, or $13 \%$ of the total daily CS presentations for each of the four partial-reinforcement groups, respectively.

Phase 4. The Permanence of the CER: Experimental Extinction

Extinction procedures were initiated when each S had met two criteria: (a) As during Phase 2, each $S$ was required to demonstrate mean suppression ratios of .10 or less for three consecutive sessions at its final shock-reinforcement schedule; and (b) all Ss had to have been exposed to an identical number of CS presentations during the entire acquisition series. Extinction was begun following a total of 1,080 conditioning trials.

Extinction sessions were identical to the training procedures, with the exception that shock was omitted following all CS presentations. All other contingencies remained in effect. Extinction was continued for $2090-\mathrm{min}$ daily sessions (300 trials) or until the mean suppression ratio exceeded .50 for a given $S$ for three consecutive sessions. Ss that extinguished in fewer than 300 trials were assigned a daily ratio of .50 for the remainder of the extinction series.

\section{RESULTS}

A Shock-reinforcement Schedule by Days analysis of variance conducted on the mean daily suppression ratios during CER 


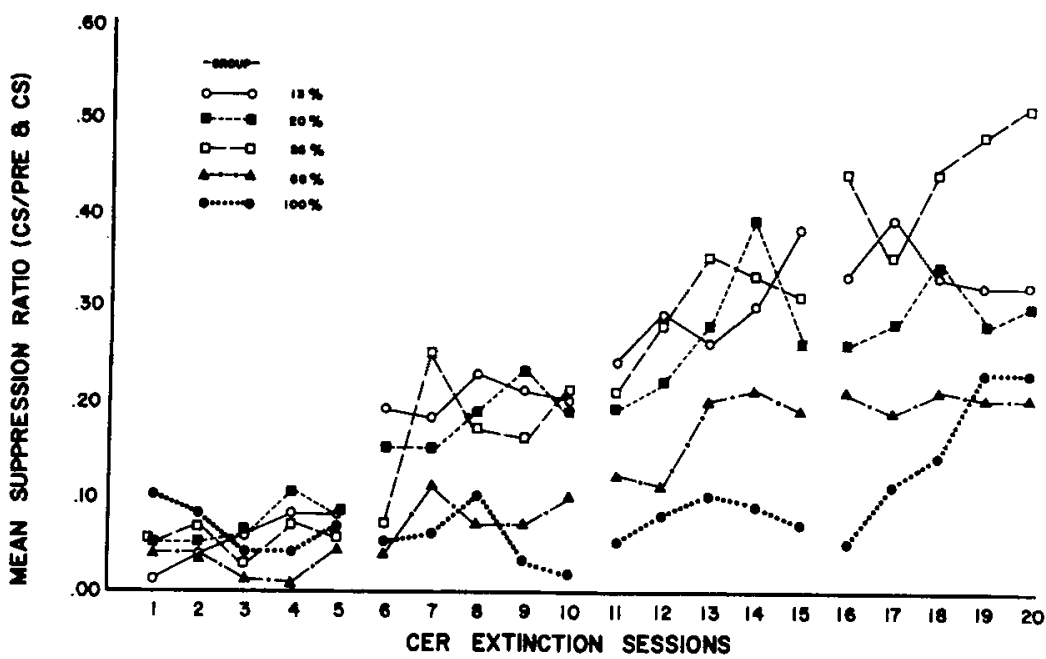

extinction revealed a significant effect of Schedule $(F=12.93, \mathrm{df}=4 / 18, \mathrm{p}<.001)$, Days $(F=4.96$, df $=19 / 76, p<.001)$, and Schedule by Days interaction $(F=4.99$, df $=76 / 372, p<.001$ ). To determine the locus of the interaction, separate one-way analyses were conducted on the mean ratios for Extinction Days 1-5, 6-10, 11-15, and 16-20. Significance was obtained only during Days 11-15 ( $F=67.41$, df $=4 / 18$, $\mathrm{p}<.001$ ). As may be seen in Fig. 1, the mean ratios for the $100 \%$ groups indicated almost no signs of attenuated suppression during the first 15 days of CER extinction-225 shock-free CS presentations. In contrast, however, suppression for the partially reinforced groups declined by more than $300 \%$ from the level observed during similar exposure to nonreinforced CS presentations.

Further a posteriori analyses revealed reliable ordered differences in resistance to extinction between the various reinforcement groups. Sheffé's test for ordered differences (Winer, 1962) showed the $100 \%$ group to be significantly different from the $66 \%$ group ( $\mathrm{p}<.05)$, and from the $26 \%, 20 \%$, and $13 \%$ groups $(p<.01)$.

$$
\text { DISCUSSION }
$$

In contrast to previous work investigating similar behavioral processes (Geller, Kailan, Stein, \& Brady, 1957; Brimer \& Dockrill, 1966; Wagner, Siegel, \& Fein, 1967), the data from the present study clearly suggest the presence of an inverse PRE, with resistance to extinction increasing rather than decreasing with increases in shock-reinforced CS presentations. The present effect most likely did not arise from the difference in absolute number of shocks received among the various groups, since previous literature (Brimer \& Dockrill, 1966) has indicated a substantial PRE regardless of differences in exposure to shock.

An alternative explanation in terms of shock density is offered. Observations of changes in baseline responding (i.e., non-CS rates) during shock-reinforcement training were differentially noted for the various groups. Although there were no discemable changes occurring in the frequency of responses emitted during CS-on times nor in the suppression ratios, rates during CS-off times substantially improved as a function of decreases in the percentage of shock-reinforced trials from the level observed during initial conditioning at $100 \%$. These initially low baseline rates probably indicated a tendency for the CER to occur to non-CS stimuli, i.e., background and apparatus cues in addition to any response-produced cues associated with the CS-US sequence. Increases in baseline response rates were evident only with decreases in shock density during continued CER training. It is suggested that the maintenance of a generalized CER in the higher shock-reinforcement groups contributed to prolonged resistance to extinction of suppression, especially in the $100 \%$ and $60 \%$ groups. It may well be that a generalized CER places limits on the rate of extinction of the CS-specific CER, and that
Fig. 1. Mean daily suppression ratios during extinction of conditioned suppression.

the amount of generalized suppression is at least partially dependent on changes in shock density. A direct test comparing various groups that are maintained on identical percentages of shock reinforcement, but that are exposed to differing degrees of shock density would be of considerable interest. Just as shock density has been demonstrated to have substantial effects on the maintenance of avoidance behavior (Boren \& Sidman, 1957), it may also be an important variable in the maintenance of classically conditioned responses controlled by aversive contingencies.

\section{REFERENCES}

ANNAU, Z, \& KAMIN, L. J. The conditioned emotional response as a function of intensity of the US. Joumal of Comparative \& Physiological Psychology, 1961, 54, 428-432.

BOREN, J. J., \& SIDMAN, M. Maintenance of avoidance behavior with intermittent shocks. Canadian Journal of Psychology, 1957, 11, 185-192.

BRIMER, C. J., \& DOCKRILL, F. J. Partial reinforcement and the CER. Psychonomic Science, 1966, 6, 185-186.

GELLER, I., KAILAN, H., STEIN, L., \& BRADY, J. V. Acquisition and extinction of conditioned "fear" as a function of partial shock-reinforcement. Paper presented at the meeting of the Eastern Psychological Association, 1957.

GRANT, D. A., \& SCHIPPER, L. M. The acquisition and extinction of conditioned eyelid responses as a function of the percentage of fixed-ratio random reinforcement. Journal of Experimental Psychology, 1952, 43, 313-320.

LEWIS, D. J. Partial reinforcement: A selective review of the literature since 1950. Psychological Bulletin, 1960, 57, 1-28.

WAGNER, A. R., SIEGEL, L. S., \& FEIN, G. G. Extinction of conditioned fear as a function of percentage of reinforcement. Journal of Comparative \& Physiological Psychology, 1967, 63,160-164.

WINER, B. J. Statistical principles in experimental design. New York: McGraw-Hill, 1962.

NOTE

1. This research is a portion of a dissertation submitted in partial fulfillment for the $\mathrm{PhD}$ degree at Southern Illinois University, and was conducted during the author's tenure as USPHS NIMH Predoctoral Fellow No. 1-F1-MH-29,059-01(PS). 